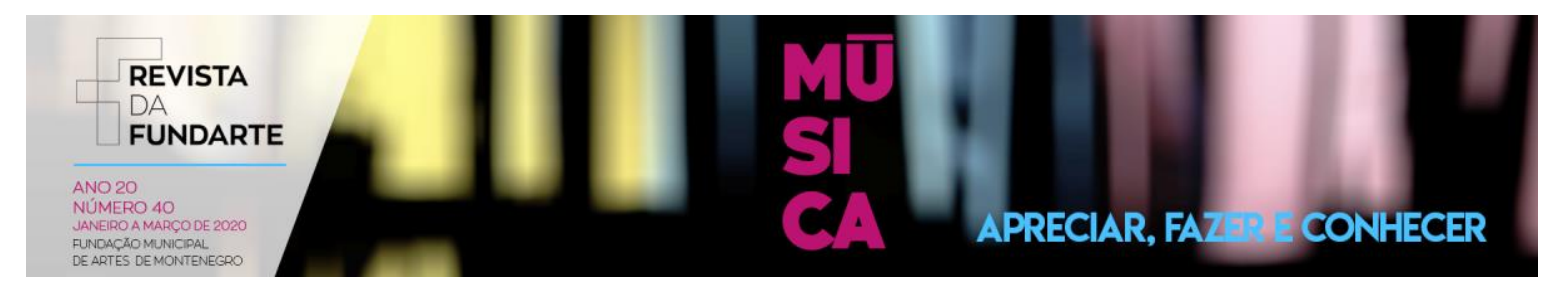

\title{
A EDUCAÇÃO ESPECIAL E O ATENDIMENTO EDUCACIONAL ESPECIALIZADO NO ENSINO SUPERIOR DE MÚSICA: UM RECORTE SOBRE QUATRO UNIVERSIDADES DO ESTADO DO RIO GRANDE DO SUL
}

Mariana Valim

Eduardo Guedes Pacheco

DOI: http://dx.doi.org/10.19179/2F2319-0868/2F747

VALIM, Mariana, PACHECO, Eduardo Guedes. A educação especial e o atendimento educacional especializado no ensino superior de música: um recorte sobre quatro universidades do Estado do Rio Grande do Sul. Revista da FUNDARTE. Montenegro, p.124-144, ano 20, o 40, janeiro/março de 2020.Disponível em: http://.seer.fundarte.rs.gov.br/index.php/RevistadaFundarte/index> 31 de março de 2020 


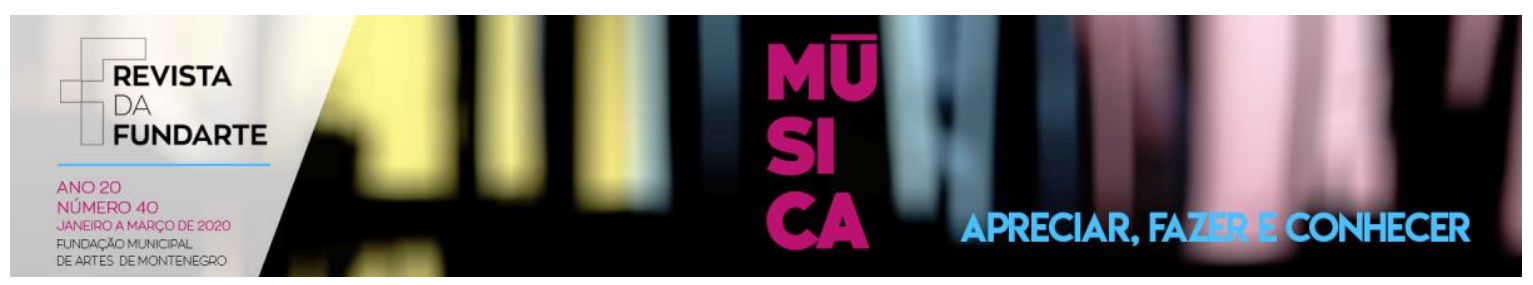

\title{
A EDUCAÇÃO ESPECIAL E O ATENDIMENTO EDUCACIONAL ESPECIALIZADO NO ENSINO SUPERIOR DE MÚSICA: UM RECORTE SOBRE QUATRO UNIVERSIDADES DO ESTADO DO RIO GRANDE DO SUL
}

\author{
Mariana Valim ${ }^{1}$ \\ Eduardo Guedes Pacheco ${ }^{2}$
}

Resumo: A Política Brasileira de Educação Especial tem sido feita, nos últimos anos, por movimentos e legislação que buscam organizar e regulamentar o acesso, a permanência, aprendizagem e recursos de atendimento pedagógico para o aluno com Necessidades Especiais. Esta pesquisa visou investigar estas regulamentações nos cursos de Licenciatura em Música, ao analisar quatro instituições de Ensino Superior no Rio Grande do Sul, para conhecer a acessibilidade da Pessoa com Deficiência no Ensino Superior de Música. Relata e analisa como estas Instituições preveem em seus regulamentos e como implementam, na prática, as condições de permanência com qualidade e garantia de acesso ao processo educativo e formativo do aluno PCD.

Palavras-chave: Educação Especial; Educação Musical; Ensino Superior de Música.

\section{SPECIAL EDUCATION AND SPECIALIZED EDUCATIONAL SERVICE IN MUSIC HIGHER EDUCATION: A PORTRAIT ABOUT FOUR UNIVERSITIES FROM THE STATE OF RIO GRANDE DO SUL}

\begin{abstract}
Over the last years, Brazilian Policy on Special Education has been implemented by movements and legislation that seek to organize and regulate the access, permanence, learning and resources of pedagogical service to students with specific necessities. This research aimed to investigate that regulations in Music Licentiate degree programs, analyzing four Higher Education Institutions in Rio Grande do Sul, to ascertain the accessibility of people with disabilities in Music Higher Education. It reports and analyzes how these Institutions foresee in their regulations and how

\footnotetext{
1 Mestranda em Educação na UERGS, linha de pesquisa Artes e Linguagens em contextos educacionais; especialista.em Alfabetização e Letramento (Faculdades São Luís) e Atendimento Educacional Especializado (UERGS); Licenciada em Música (ISEI) e em Pedagogia (ULBRA). Educadora musical nos Anos Iniciais do Ensino Fundamental e Educação Infantil na Rede Municipal de Ivoti, pianista na Orquestra Eintracht.

2 Possui graduação em Música, Bacharel - opção: Percussão pela Universidade Federal de Santa Maria (2001) e mestrado em Educação pela Universidade Federal de Santa Maria (2005). É doutor pela Universidade Federal do Rio Grande do Sul na linha de Pesquisa Filosofias da Diferença e da Educação. Professor da Universidade Estadual do Rio Grande do Sul, tem seu trabalho voltado para a formação de professores interessados em problematizar sobre a arte dentro do contexto educacional. Atua como instrumentista solo de percussão procurando trabalhar em espaços identificados com a educação, na perspectiva de aproximar o fazer artístico das discussões que envolvem o campo da Educação.
}

VALIM, Mariana, PACHECO, Eduardo Guedes. A educação especial e o atendimento educacional especializado no ensino superior de música: um recorte sobre quatro universidades do Estado do Rio Grande do Sul. Revista da FUNDARTE. Montenegro, p.124-144, ano 20, no 40, janeiro/março de 2020.Disponível em: http://.seer.fundarte.rs.gov.br/index.php/RevistadaFundarte/index> 31 de março de 2020 


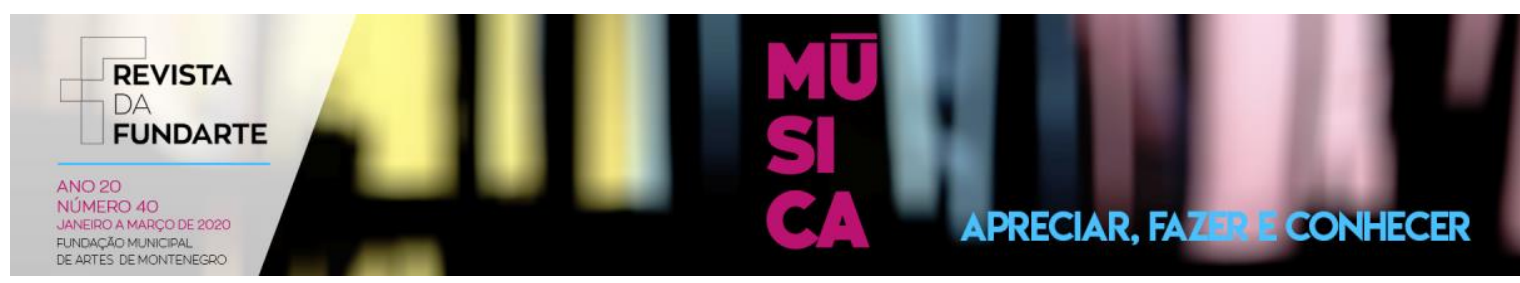

they implement in practice the conditions of quality permanence and guarantee of access to the educational and formation process of the students with disabilities.

Keywords: Special Education; Music Education; Music Higher Education.

\section{Introdução}

A Política Brasileira de Educação Especial foi feita, nos últimos anos, por movimentos e legislações para regulamentar o acesso e a permanência da Pessoa com Deficiência (PCD) no ensino regular comum. Entram aqui as normativas, decretos e leis que asseguram o acesso e continuidade de grupos e indivíduos à educação formal, para que a Pessoa com Deficiência possa frequentar a escola regular comum, com serviço de apoio.

Para este serviço de apoio, o Atendimento Educacional Especializado (AEE) é instituído, através de legislações específicas. A mais recente é a do Decreto №. 7.611/11, e é denominado como "o conjunto de atividades, recursos de acessibilidade e pedagógicos, organizados institucional e continuamente" (BRASIL, 2011). Prevê que as medidas de complementação e/ou suplementação à formação "maximizem o desenvolvimento acadêmico e social" (BRASIL, 2011), com objetivo de "prover condições de acesso, participação e aprendizagem no ensino regular, e garantir serviços de apoio especializados de acordo com as necessidades individuais dos estudantes, (...) voltado a eliminar barreiras que possam obstruir 0 processo de escolarização de estudantes com deficiência, transtornos globais do desenvolvimento e altas habilidades ou superdotação" (BRASIL, 2011).

As diretrizes da Política Nacional de Educação Especial, na perspectiva da Educação Inclusiva (BRASIL, 2008), tratam sobre como se efetiva a Educação Especial no Ensino Superior, objetivando as ações que os sistemas de ensino precisam dispor ao aluno, público-alvo desta modalidade de ensino.

$\mathrm{Na}$ Educação Superior, a transversalidade da Educação Especial se efetiva por meio de ações que promovam o acesso, a permanência e a participação dos alunos. Estas ações envolvem o planejamento e a organização de recursos e serviços para a promoção da acessibilidade arquitetônica, nas comunicações, nos sistemas de informação, nos materiais didáticos e

VALIM, Mariana, PACHECO, Eduardo Guedes. A educação especial e o atendimento educacional especializado no ensino superior de música: um recorte sobre quatro universidades do Estado do Rio Grande do Sul. Revista da FUNDARTE. Montenegro, p.124-144, ano 20, no 40, janeiro/março de 2020.Disponível em: http://.seer.fundarte.rs.gov.br/index.php/RevistadaFundarte/index> 31 de março de 2020 


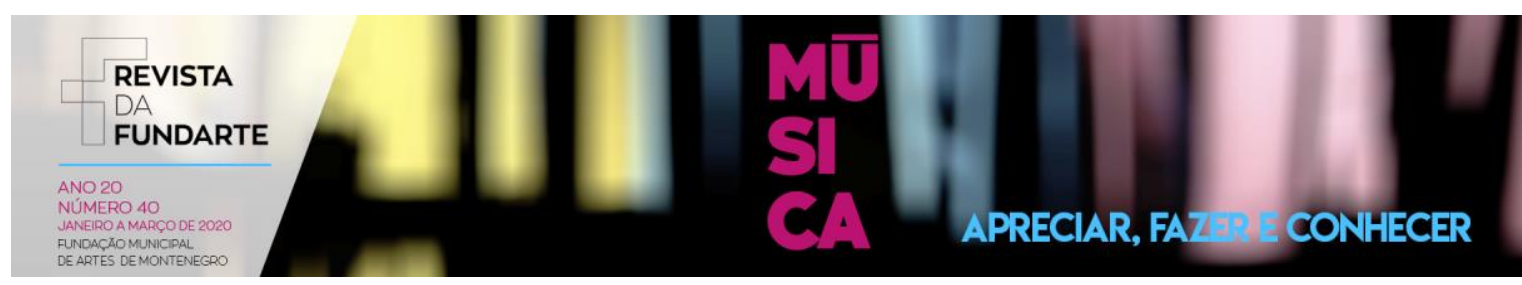

pedagógicos, que devem ser disponibilizados nos processos seletivos e no desenvolvimento de todas as atividades que envolvem o ensino, a pesquisa e a extensão (BRASIL, 2008).

A partir dessa premissa, as ações para o acesso, permanência e participação do aluno nos processos seletivos e desenvolvimento de todas as atividades do Ensino Superior, são: planejamento e organização de recursos e serviços para promoção das várias acessibilidades (arquitetônica, comunicações, informações, materiais didáticos e pedagógicos).

\section{O Ensino Superior de Música}

Com as Políticas Nacionais e legislações de Educação Especial inclusiva em todos os níveis, a Pessoa com Deficiência passa a ter acessibilidade também ao Ensino Superior de Música e à formação em Licenciatura, que tem como finalidade a profissionalização de docentes. Para que isso realmente se efetive como um processo inclusivo e possível de formação profissional da PCD, há necessidade de que as medidas e diretrizes previstas para o acesso, permanência e participação na Educação Especial sejam aplicadas, adaptadas e vigoradas nos Sistemas de Ensino.

Viviane Louro, em sua obra Fundamentos da aprendizagem musical da pessoa com deficiência, fala sobre o Paradigma de Suporte, o conceito atual em relação à Inclusão, que parte do pressuposto que

a pessoa com deficiência tem direito à convivência não segregada e ao acesso imediato e contínuo aos direitos disponíveis aos demais cidadãos. No entanto, para que isso aconteça, é necessário que haja um suporte (social, econômico, físico ou instrumental), um meio que garanta o acesso a todo e qualquer recurso da comunidade. (LOURO, 2012, p. 27).

Analisa que o Paradigma de Suporte é um processo bidirecional, seja entre sociedade-pessoa com deficiência, professor-aluno, escola-aluno, empresa-

VALIM, Mariana, PACHECO, Eduardo Guedes. A educação especial e o atendimento educacional especializado no ensino superior de música: um recorte sobre quatro universidades do Estado do Rio Grande do Sul. Revista da FUNDARTE. Montenegro, p.124-144, ano 20, no 40, janeiro/março de 2020.Disponível em: http://.seer.fundarte.rs.gov.br/index.php/RevistadaFundarte/index> 31 de março de 2020 


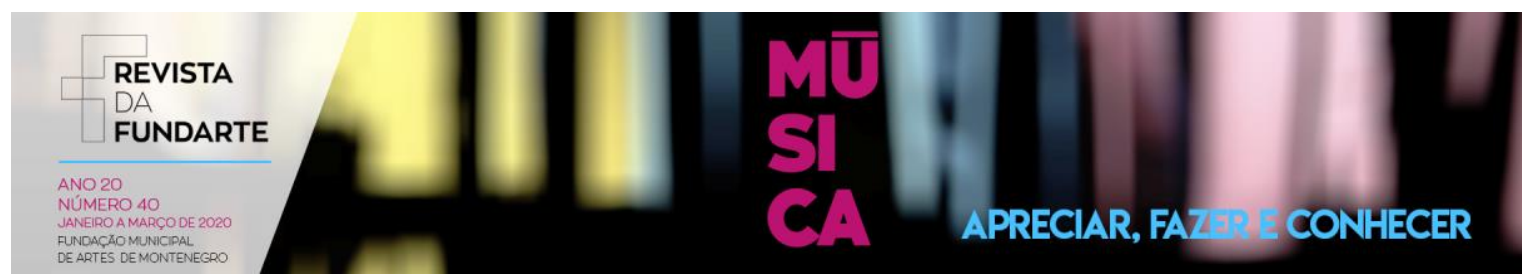

funcionário, etc. Sinaliza a importância do acesso à cultura e às artes para toda a população, sem exceções e a inclusão no ambiente musical, seja qual for.

Em seu artigo Música e Inclusão nas Universidades (BARROSO, 2016 p.155), Maria Aida Barroso cita três aspectos que considera indissociáveis em relação a este tema: garantir formação necessária ao licenciando para atuar na educação musical inclusiva, a conclusão do Ensino Superior e ingresso no mercado de trabalho da PCD e viabilizar o acesso da PCD para a docência no Ensino Superior. Entende como fundamental o diálogo constante com a comunidade acadêmica e o aluno com deficiência, buscando informações e ações mais eficientes para sua efetiva inclusão e formação.

Essas pesquisas contribuem para o avanço das discussões de acesso e permanência da pessoa com deficiência no Ensino Superior de Música, traçando paralelos e ações entre a educação musical e educação especial, e que contribuíram com a elaboração deste trabalho, tendo como base a análise de quatro instituições de Ensino Superior, sendo duas privadas e duas públicas. Tratam sobre as questões que envolvem a Educação Especial nos seus cursos de Licenciatura em Música. Foi realizada uma pesquisa multicaso, consultando os seguintes documentos destas Instituições: Regimentos Gerais, Plano de Desenvolvimento Institucional (PDI), Plano Político-Pedagógico de Curso e editais de ingresso/vestibular mais recente, investigando se estes documentos previam a Educação Especial inclusiva em seu texto. Depois, os coordenadores de curso e/ou gestores foram entrevistados, possibilitando lançar um olhar investigativo sobre as condições de acesso e permanência dos alunos PCD diante da demanda recebida. As quatro instituições, assim como os coordenadores/gestores das mesmas, como forma de preservar o sigilo de contrato, foram nomeadas por Instituição A, B, C e D.

Para efetivar a Inclusão, a Política Nacional de Educação Especial na perspectiva da Educação Inclusiva, trata sobre as ações que os sistemas de ensino precisam dispor ao aluno que é seu público-alvo.

VALIM, Mariana, PACHECO, Eduardo Guedes. A educação especial e o atendimento educacional especializado no ensino superior de música: um recorte sobre quatro universidades do Estado do Rio Grande do Sul. Revista da FUNDARTE. Montenegro, p.124-144, ano 20, no 40, janeiro/março de 2020.Disponível em: http://.seer.fundarte.rs.gov.br/index.php/RevistadaFundarte/index> 31 de março de 2020 


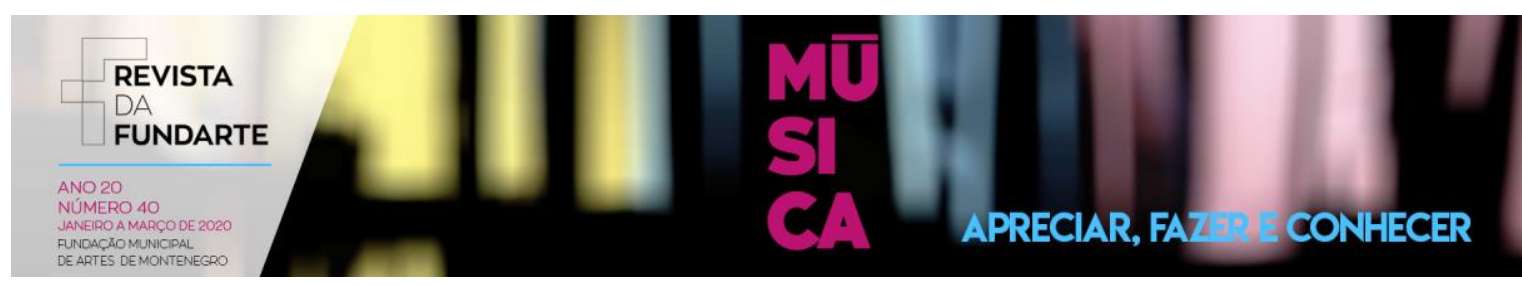

Na Educação Superior, a transversalidade da Educação Especial se efetiva por meio de ações que promovam o acesso, a permanência e a participação dos alunos. Estas ações envolvem o planejamento e a organização de recursos e serviços para a promoção da acessibilidade arquitetônica, nas comunicações, nos sistemas de informação, nos materiais didáticos e pedagógicos, que devem ser disponibilizados nos processos seletivos e no desenvolvimento de todas as atividades que envolvem o ensino, a pesquisa e a extensão.(BRASIL, 2008).

Tendo como norte nessa premissa de ações objetivas, os capítulos dessa análise foram organizados de acordo com os itens desta diretriz, contemplando os seguintes aspectos: acesso (ingresso e acessibilidade e barreiras), permanência (recursos, serviços de apoio e/ou AEE, adaptações curriculares, avaliações, inclusão profissional) e participação no ensino, pesquisa e extensão (formação discente e formação docente).

\section{Acesso}

A garantia de acesso à PCD seriam todas as medidas tomadas "nos processos seletivos para ingresso e permanência nos cursos oferecidos pelas instituições de ensino superior (...)" (BRASIL, 2015, p. 35). Foram aqui divididos em duas partes para descrição: a primeira, relativa aos processos de ingresso no Nível Superior, como vestibulares e outras provas; a segunda, relativa à acessibilidade e/ou barreiras ao ingresso, assim como utilização, acolhimento e funcionalidade com autonomia ao ingressar na Instituição de Ensino Superior de Música.

\section{Ingresso}

De acordo com o Artigo 30 do Estatuto da Pessoa com Deficiência, nos processos seletivos das instituições de Ensino Superior, as medidas adotadas para acesso da PCD e previamente solicitadas pelo candidato com deficiência são: recursos de tecnologia ou de acessibilidade, dilatação de tempo, adaptação de avaliação e redação da modalidade escrita da Língua Portuguesa e tradução do edital em LIBRAS (BRASIL, 2015).

VALIM, Mariana, PACHECO, Eduardo Guedes. A educação especial e o atendimento educacional especializado no ensino superior de música: um recorte sobre quatro universidades do Estado do Rio Grande do Sul. Revista da FUNDARTE. Montenegro, p.124-144, ano 20, no 40, janeiro/março de 2020.Disponível em: http://.seer.fundarte.rs.gov.br/index.php/RevistadaFundarte/index> 31 de março de 2020 


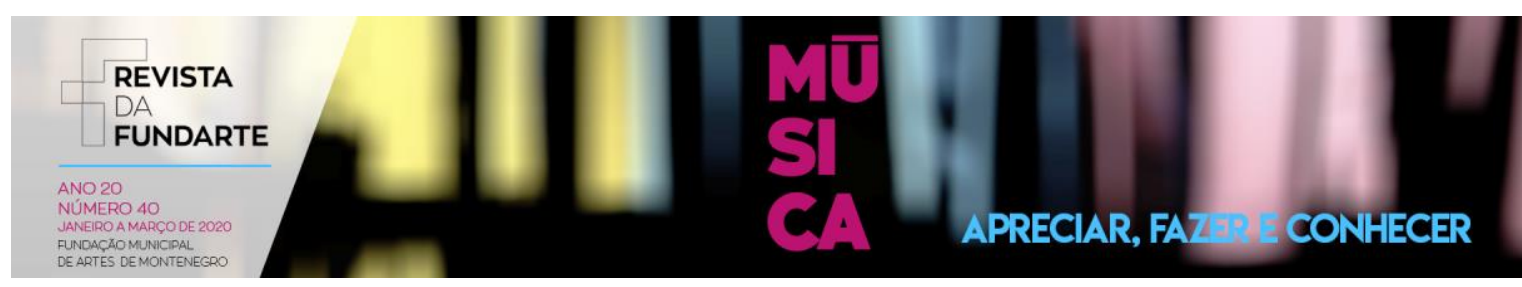

Quanto aos Regulamentos ou Regimentos, na maioria dos textos analisados, aparecia o estabelecimento de cotas de ingresso e citava também a permanência dos alunos PCD quando tratava sobre os processos de ingresso dos discentes. Em todos os Editais de Processo de Vestibular havia uma seção ou pergunta sobre acessibilidade, onde o candidato solicitava recurso ou atendimento diferenciado e depois descrevia que tipo de atendimento necessitava durante a prova.

A Instituição $A$, oferece o edital do vestibular no formato de vídeo em LIBRAS e acessibilidade para o Teste de Habilitação Específico. A Instituição D, solicita, no formulário de inscrição, que o candidato com deficiência entrasse em contato por email para a solicitação de acessibilidade. Os coordenadores/gestores B e C também citaram, em suas entrevistas, estes campos específicos nos editais de vestibular, relatando os recursos tecnológicos e de apoio utilizados, como ledores, escreventes, intérpretes, dilatação de tempo, acessibilidade de local, uso de computadores, etc.

\section{Acessibilidade e barreiras}

Apresentam-se os conceitos tratados no Estatuto da Pessoa com Deficiência (BRASIL, 2015, p. 20), sobre acessibilidade: prover condições para que a pessoa com deficiência ou mobilidade reduzida possa utilizar e transitar, com segurança e autonomia, nos espaços públicos ou privados de uso coletivo. Barreira seria qualquer obstáculo ou empecilho que limite ou impeça a participação social, direitos, liberdade e acesso da pessoa com deficiência, classificadas em: urbanísticas, arquitetônicas, nos transportes, comunicações e informações, atitudinais e tecnológicas.

Em relação à infraestrutura física, as Instituições demonstram preocupação com os espaços e recursos, como salas de aula, biblioteca e informatização, citando a adequação e acessibilidade de cada prédio para o acesso universal de PCD. A Instituição A funciona em um prédio muito antigo, com dificuldades para o acesso e utilização de PCD, como relatou a coordenação. Uma rampa de elevação foi instalada na entrada do prédio, com treinamento para os funcionários da portaria VALIM, Mariana, PACHECO, Eduardo Guedes. A educação especial e o atendimento educacional especializado no ensino superior de música: um recorte sobre quatro universidades do Estado do Rio Grande do Sul. Revista da FUNDARTE. Montenegro, p.124-144, ano 20, no 40, janeiro/março de 2020.Disponível em: http://.seer.fundarte.rs.gov.br/index.php/RevistadaFundarte/index> 31 de março de 2020 


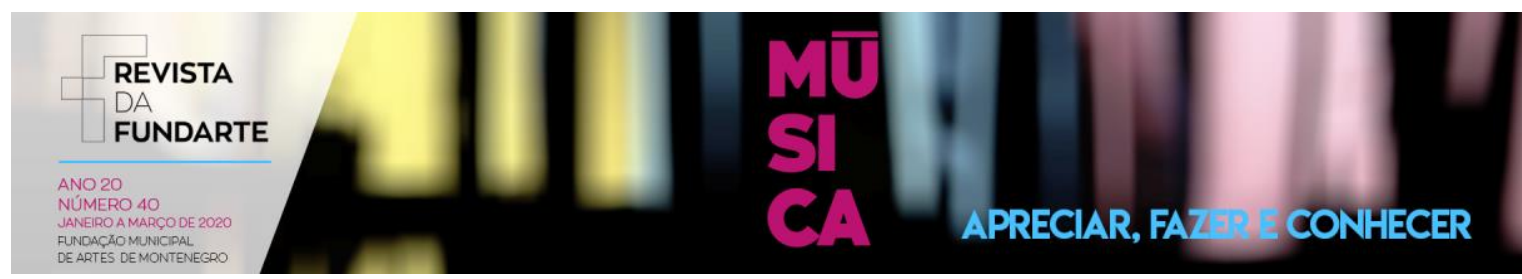

poderem operar quando necessário. A Instituição B funciona em um prédio com elevador, mas este não tinha as inscrições em Braille e sinais sonoros, e o piso no entorno e dentro do prédio não era tátil. As Instituições $C$ e $D$ têm prédios muito antigos, com escadas e portas estreitas, portanto, construíram e/ou adaptaram um prédio de acordo com as normas de acessibilidade, como rampas de acesso, elevadores e banheiros acessíveis, e, na impossibilidade de o estudante acessar os andares superiores, as aulas poderiam ser realizadas nos andares térreos. $\mathrm{Na}$ Instituição $\mathrm{C}$, foram citadas metas e incluídas na descrição dos espaços e materiais com infraestrutura adequada às PCD em seu PDI, em capítulo especificamente destinado à Educação Inclusiva.

Em relação às barreiras, todos os coordenadores/gestores, com exceção da Instituição $A$, relataram atitudes de acesso e acolhimento por parte das Instituições e da maioria dos profissionais, mas ainda com barreiras atitudinais de alguns docentes, funcionários e estudantes em relação à Inclusão da PCD no Ensino Superior. $\mathrm{Na}$ Instituição $\mathrm{B}$, foi citada a barreira do transporte, ao relatar a dificuldade de um aluno com deficiência visual, que morava em uma cidade pequena e longe do campus, ao se locomover através de transporte público.

\section{Permanência:}

As garantias da permanência da PCD no Ensino Superior seriam todas as medidas que favoreçam a aprendizagem e "maximizem o desenvolvimento acadêmico e social dos estudantes com deficiência", para "atender às características dos estudantes com deficiência e garantir seu pleno acesso ao currículo em condições de igualdade, promovendo a conquista e o exercício de sua autonomia" (BRASIL, 2015, p.3).

\section{Recursos}

Os recursos seriam os itens de tecnologia assistiva ou ajuda técnica que promovam a funcionalidade e aprendizagem da PCD durante o curso, podendo citar: VALIM, Mariana, PACHECO, Eduardo Guedes. A educação especial e o atendimento educacional especializado no ensino superior de música: um recorte sobre quatro universidades do Estado do Rio Grande do Sul. Revista da FUNDARTE. Montenegro, p.124-144, ano 20, no 40, janeiro/março de 2020.Disponível em: http://.seer.fundarte.rs.gov.br/index.php/RevistadaFundarte/index> 31 de março de 2020 


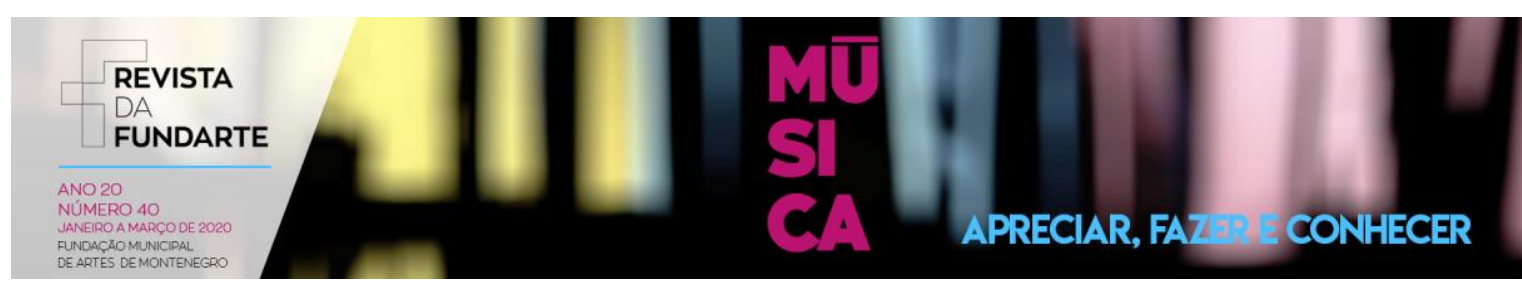

material didático em diversos formatos de acessibilidade, assim como, demais recursos de tecnologia assistiva, tais como: scanner com voz, impressora e máquina Braille, software de comunicação alternativa, sistema de frequência modulada, além de serviços de tradução e interpretação da Língua Brasileira de Sinais e do atendimento educacional especializado. (BRASIL, 2014, p.2).

Os coordenadores relatam utilizar recursos individualizados, de acordo com as solicitações de cada estudante e/ou professor, conforme demanda e necessidade solicitada. $\mathrm{Na}$ Instituição $\mathrm{A}$, é realizada uma reunião com professores, coordenadores de curso e profissionais do Núcleo de Inclusão e Acessibilidade, para decidirem qual recurso utilizar nas aulas, ou para adaptação de materiais, relatando utilização de programa de leitor de tela e recursos de áudio para escuta das músicas e partituras anteriormente. Na Instituição B, é enviado ao Núcleo de Atendimento Discente, toda a necessidade do estudante, porém, como esse núcleo fica distante do campus e atende à demanda de alunos de toda a Universidade, por vezes demora ou impossibilita utilizar esse recurso durante as aulas, portanto, o próprio professor realiza a adaptação necessária. Foi mencionada a utilização de softwares de áudios e ledores no próprio equipamento tecnológico do aluno, assim como a transcrição de algumas partituras em MusiBraille e textos para o formato .doc ou .txt. A Instituição C realiza uma reunião antes de o semestre começar com a coordenação e aluno, e disponibiliza recursos tecnológicos na Instituição para o estudante, como software de ledores na Biblioteca. A Instituição $D$ também realiza reuniões antes de começar o semestre, com coordenação e discentes, para avaliar as necessidades dos estudantes com deficiência. Não especificou nenhum recurso por não ter necessidade atualmente.

\section{Serviços de apoio e/ou AEE}

Os serviços de profissionais de apoio e de Atendimento Educacional Especializado representam a parte de recursos humanos, relativos às pessoas e/ou

VALIM, Mariana, PACHECO, Eduardo Guedes. A educação especial e o atendimento educacional especializado no ensino superior de música: um recorte sobre quatro universidades do Estado do Rio Grande do Sul. Revista da FUNDARTE. Montenegro, p.124-144, ano 20, no 40, janeiro/março de 2020.Disponível em: http://.seer.fundarte.rs.gov.br/index.php/RevistadaFundarte/index> 31 de março de 2020 


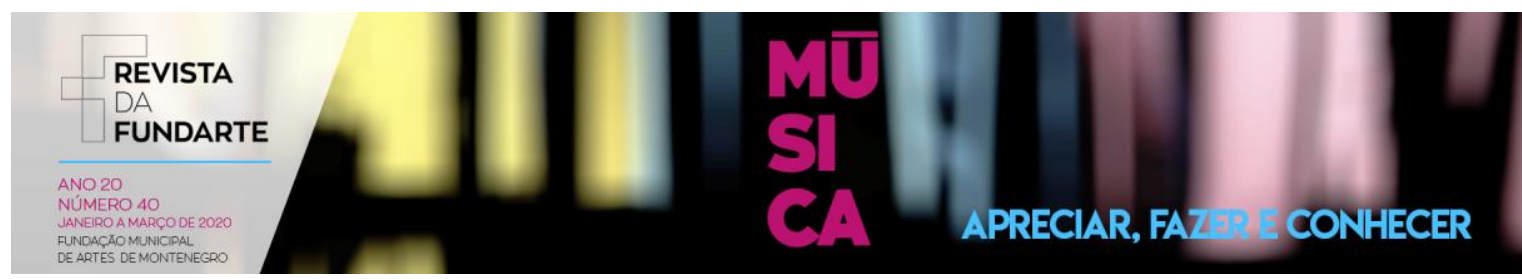

profissionais da Instituição que realizem o Atendimento Educacional Especializado e outras ações, realizadas em um espaço específico, como Núcleos de Acessibilidade ou Sala de Recursos, ou em qualquer outro espaço de aprendizagem do aluno, que viabilizam "a melhoria da qualidade do processo educacional dos alunos" (BRASIL, 2009, p.3).

A Instituição A possui três Núcleos de inclusão: um deles atende as questões referentes à utilização de Libras; outro, o apoio para alunos com deficiência visual; e o último, conta com profissionais da área da saúde e Educação Especial, intérpretes, atendentes especializados, monitores, assistência social, serviço de Psicologia, inclusive um bolsista do curso de Música que atende as demais necessidades da pessoa com alguma limitação. A Instituição $B$, através de seu Núcleo discente, poderia dispor de pessoal especializado durante as aulas, de acordo com a necessidade do aluno, porém a coordenação relata que, devido à redução de recursos orçamentários, dispõe, atualmente, somente de assessoria para atendimento e recursos de tecnologia assistiva. Afirma que "não ter um Núcleo de Acessibilidade é uma barreira" (Coordenador B), pois as adaptações e recursos só acontecem de acordo com a demanda, e com atraso, pois quem os faz é o próprio professor.

A Instituição $C$ oferece um espaço de atendimento ao estudante com deficiência, alunos e comunidade, em parceria com um curso de Bacharelado na área da saúde, para atendimento terapêutico, com profissionais docentes e espaço para aprendizagem e vivência dos alunos dos dois cursos de graduação. Também "realizam reuniões mensais com profissional de AEE, Psicopedagogos, Pedagogos para discutirem pedagogicamente, metodologicamente e, principalmente, sobre avaliação" (Coordenador $\mathrm{C}$ ). Dispõe de um professor de apoio, com experiência e formação na área, assim como monitores que realizam aulas de reforço no contra turno para ajudar no desenvolvimento dos alunos com dificuldade de aprendizagem e/ou deficiência. Essa monitoria faz parte do programa de formação do licenciando

VALIM, Mariana, PACHECO, Eduardo Guedes. A educação especial e o atendimento educacional especializado no ensino superior de música: um recorte sobre quatro universidades do Estado do Rio Grande do Sul. Revista da FUNDARTE. Montenegro, p.124-144, ano 20, o 40, janeiro/março de 2020.Disponível em: http://.seer.fundarte.rs.gov.br/index.php/RevistadaFundarte/index> 31 de março de 2020 


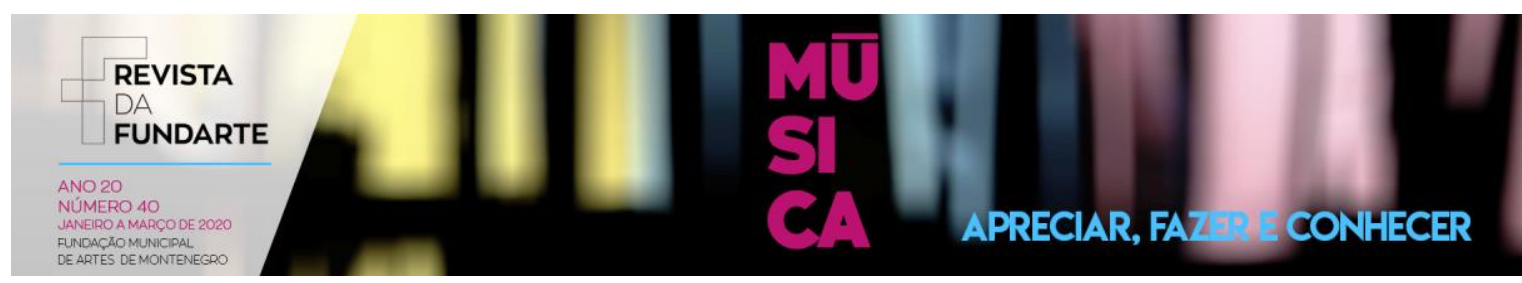

em Música na Instituição, com carga horária a ser cumprida em experiência de ensino para PCD.

A Instituição D realiza, com a Diretora de Ensino e a Coordenação de Curso, entrevistas e disponibilização dos recursos humanos necessários para o estudante com deficiência. Não havia profissional específico para o AEE, mas por vezes se designa um professor de Música da Instituição para que desenvolva atividades de reforço na aprendizagem musical, individual e coletivamente em classes que leciona. Busca parcerias e formação com professores de outros lugares e profissionais da saúde que atendam estes alunos (Psiquiatras, Neurologistas), para entender cada caso. Esta Instituição citou também busca de assessoria em questões legais e jurídicas, para entender as legislações sobre a Pessoa com Deficiência no Ensino Superior com formação de professores (cursos de licenciatura), para a adaptação curricular, participação em estágios com monitoria de turma e continuidade dos alunos PCD, preocupando-se com o encaminhamento ao trabalho.

\section{Adaptações curriculares}

As adaptações curriculares são os recursos didáticos, pedagógicos e metodológicos que permitem modificações do currículo e aplicação de metodologias específicas para cada deficiência, que favoreça a aprendizagem do aluno e práticas pedagógicas inclusivas. Na legislação, especifica que sejam feitas adaptações razoáveis, decididas em equipe multidisciplinar, que "não acarretem ônus desproporcionais ou indevidos" (BRASIL, 2015, p.22) aos direitos de aprendizagem da PCD, ou seja, garantir "o pleno acesso ao currículo em condições de igualdade" (p.33), estabelecendo um equilíbrio entre a aprendizagem de qualidade e condizente com os objetivos curriculares do curso, e as barreiras acadêmicas, que seriam um obstáculo ao desenvolvimento e formação do estudante. A "recusa de adaptações razoáveis e de fornecimento de tecnologias assistivas", considera-se "discriminação em razão da deficiência" (p.24).

VALIM, Mariana, PACHECO, Eduardo Guedes. A educação especial e o atendimento educacional especializado no ensino superior de música: um recorte sobre quatro universidades do Estado do Rio Grande do Sul. Revista da FUNDARTE. Montenegro, p.124-144, ano 20, no 40, janeiro/março de 2020.Disponível em: http://.seer.fundarte.rs.gov.br/index.php/RevistadaFundarte/index> 31 de março de 2020 


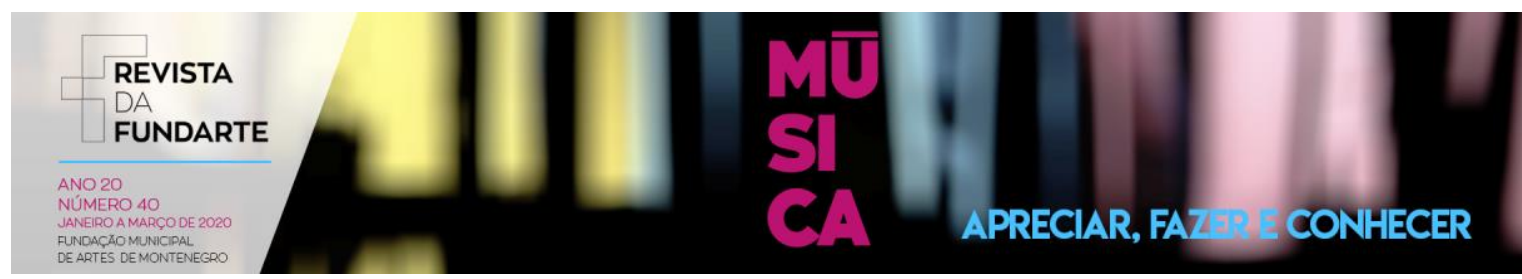

A Instituição A, no início do semestre, realiza reuniões de equipe do núcleo de acessibilidade com a coordenação do curso e o professor da disciplina que o aluno cursará no semestre, e discute a necessidade de adaptação dos objetivos da disciplina ou não, baseados no histórico do aluno, na Instituição e no conhecimento prévio do caso do aluno, com estudo feito pelo núcleo. Estas reuniões também ocorrem nas outras Instituições, mas cada uma com os responsáveis pela acessibilidade do aluno PCD.

As Instituições entendem como necessária a adaptação para alguns alunos, em disciplinas práticas, no caso de limitação física; e com as disciplinas teóricas para alunos com limitação cognitiva, mas que nem todos que são público-alvo têm necessidade de adaptação curricular, pois apresentam condições de acompanhar o currículo com o auxílio de recursos adequados.

\section{Avaliações}

As medidas de avaliação citadas no Estatuto da Deficiência para os processos seletivos para ingresso e permanência (grifo nosso) no Ensino Superior, como instrumentos de aferição e seleção do conhecimento, são: disponibilização de provas em formatos acessíveis, disponibilização de recursos de acessibilidade e tecnologia assistiva adequados, dilatação de tempo, adoção de critérios de avaliação que considerem as singularidades linguísticas na modalidade escrita da Língua Portuguesa e tradução para LIBRAS (BRASIL, 2015), tem relação direta com as adaptações razoáveis para igualdade de condições feitas no item anterior e a adoção de critérios de avaliação que levem em conta as singularidades de cada estudante com deficiência.

A Instituição A relata a avaliação feita considerando cada caso e expressa em forma de conceito. Cita caso de alunos com deficiência visual em que as seguintes medidas foram realizadas: prova em musicografia Braille aplicada em separado, com atendimento de um monitor/leitor, provas teóricas feitas de modo oral, com registro escrito pelo monitor.

VALIM, Mariana, PACHECO, Eduardo Guedes. A educação especial e o atendimento educacional especializado no ensino superior de música: um recorte sobre quatro universidades do Estado do Rio Grande do Sul. Revista da FUNDARTE. Montenegro, p.124-144, ano 20, no 40, janeiro/março de 2020.Disponível em: http://.seer.fundarte.rs.gov.br/index.php/RevistadaFundarte/index> 31 de março de 2020 


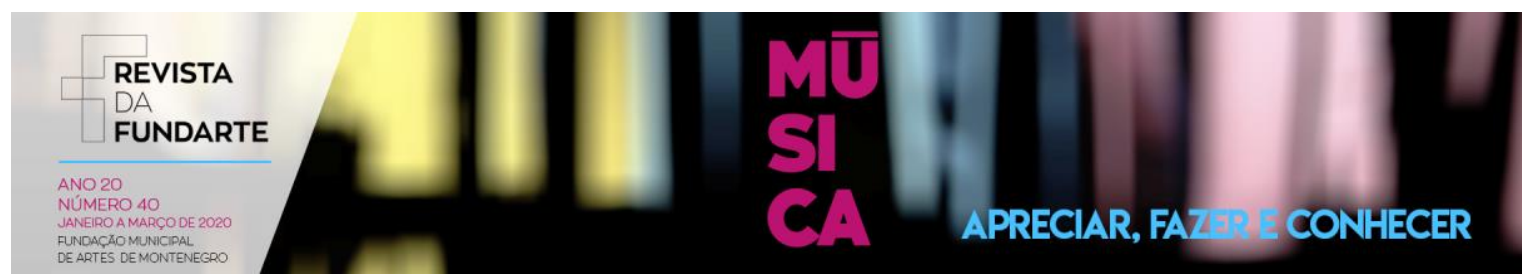

$\mathrm{Na}$ Instituição $\mathrm{B}$, relata-se adaptações e avaliações de acordo com os objetivos da disciplina e os recursos utilizados, porém nem sempre as Instituições conseguem garantir a permanência dos estudantes PCD no Ensino Superior, tornando-se uma barreira a falta de recursos e ajuda técnica. Confirma que alguns estudantes PCD não necessitariam de avaliações ou adaptações diferenciadas em relação ao nível intelectual do conhecimento se tivessem os recursos necessários disponíveis para sua aprendizagem, mas que acabam desistindo do curso por não terem suporte, tanto familiar, quanto Institucional.

A Instituição C cita em seu PDI as medidas de avaliação adaptadas para PCD. No capítulo de avaliação falava sobre o caráter processual desta e a possibilidade de o professor realizar utilizando os instrumentos que achasse adequado. Cita dilatação de tempo, possibilidade de consulta de materiais, apoio emocional para transtornos psicológicos. Na Instituição D, adotavam a avaliação processual durante o semestre, caso a caso, citando uma aluna com degeneração muscular que realizava a prova de violão até o limite do cansaço muscular, estendendo o tempo para a realização com intervalos para descanso, registrando em relatório o que foi realizado.

\section{Inclusão profissional}

Segundo o Estatuto da Pessoa com Deficiência, "é vedada restrição ao trabalho da pessoa com deficiência e qualquer discriminação em razão de sua condição, (...) bem como exigência de aptidão plena” (BRASIL, 2015, p.38). Como formador de profissionais da educação, os cursos de Licenciatura em Música precisam oferecer ações articuladas com diversos setores, indicados por equipes multidisciplinares, para que a "pessoa com deficiência possa ingressar, continuar ou retornar ao campo de trabalho, respeitados sua livre escolha, sua vocação e seu interesse" (ibid.), como a habilitação do estudante para o exercício da profissão de educador musical e encaminhamento ao mercado de trabalho. de acordo com a formação do curso.

VALIM, Mariana, PACHECO, Eduardo Guedes. A educação especial e o atendimento educacional especializado no ensino superior de música: um recorte sobre quatro universidades do Estado do Rio Grande do Sul. Revista da FUNDARTE. Montenegro, p.124-144, ano 20, no 40, janeiro/março de 2020.Disponível em: http://.seer.fundarte.rs.gov.br/index.php/RevistadaFundarte/index> 31 de março de 2020 


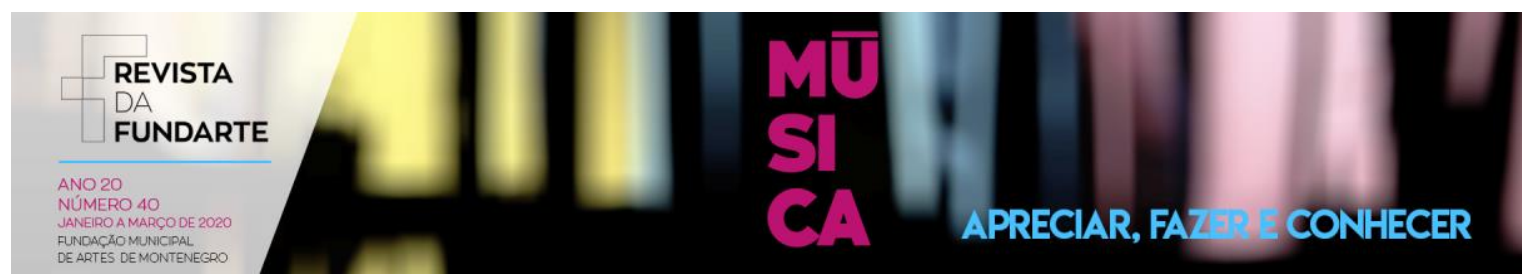

A Instituição A, afirma que os estudantes PCD cursam as disciplinas regularmente e se graduam como todos os outros alunos, recebendo seu diploma e habilitação para o trabalho em condições de igualdade. A Instituição B relata a preparação do aluno PCD como qualquer outro para que as escolas acolham os profissionais com deficiência, pois estes têm muito a contribuir na educação, afirmando que o aluno é o gerador e validador das ações inclusivas, exemplificando com o caso de uma estudante com baixa visão que alcançou a graduação no curso.

O coordenador $\mathrm{C}$ comenta que a sociedade e as escolas nem sempre estão preparadas para acolher a diversidade, principalmente no que denomina escolas de aprovação, com metodologias para desempenho em vestibular, que não tem interesse em profissionais e estudantes PCD que precisam de mais atendimento e investimento. Ao trabalhar com as pessoas sobre suas compreensões e entendimentos voltados para a inclusão, são formados melhores profissionais, que sabem trabalhar como equipe em cooperação, buscando amenizar barreiras, principalmente as atitudinais, para acolher a diversidade. A própria Instituição acolhe funcionários PCD, sendo um deles cego e autista, e outra, cadeirante.

O coordenador D relata a preocupação com a recepção dos alunos nos espaços educativos, no desempenho das suas funções de docência, as barreiras atitudinais de pais, diretores, professores e comunidade escolar. Sugere repensar as carreiras e a função do Ensino Superior para a Pessoa com Deficiência e questiona a concessão de um diploma em algumas situações em que o aluno tenha limitações para monitoria de turma e crianças, representando um certificado de habilitação plena sem que esteja completamente habilitado.

\section{Participação no ensino, pesquisa e extensão}

A garantia de participação da PCD no Ensino Superior seriam todas as medidas que multiplicassem os saberes sobre a inclusão da pessoa com deficiência no âmbito do Ensino Superior, seja por ela mesma como compartilhamento de experiências e pesquisas, como pelo ensino realizado pela Instituição na área da VALIM, Mariana, PACHECO, Eduardo Guedes. A educação especial e o atendimento educacional especializado no ensino superior de música: um recorte sobre quatro universidades do Estado do Rio Grande do Sul. Revista da FUNDARTE. Montenegro, p.124-144, ano 20, no 40, janeiro/março de 2020.Disponível em: http://.seer.fundarte.rs.gov.br/index.php/RevistadaFundarte/index> 31 de março de 2020 


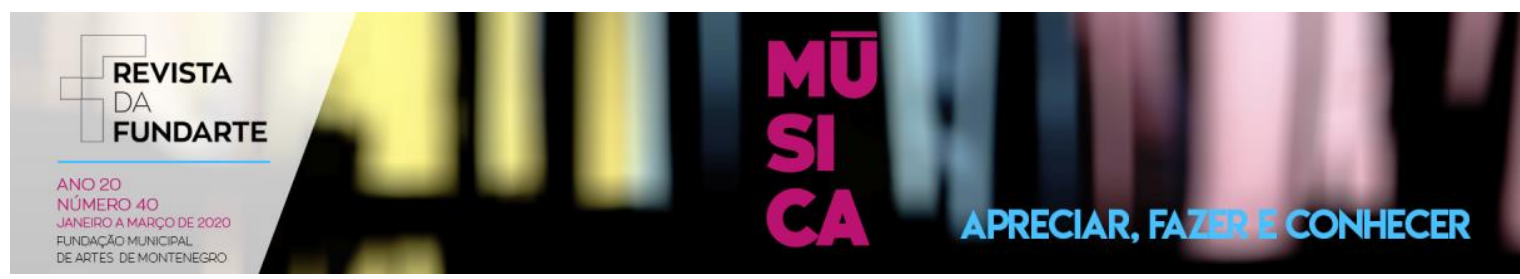

Educação Especial. Aqui foram divididos em formação discente e docente. A primeira corresponde ao que a Instituição oferece, para a formação inicial de seus estudantes de Licenciatura, de temas relacionados à atuação na educação inclusiva, seja na matriz curricular, nas práticas, nos cursos de extensão e pesquisas. A segunda, à formação continuada e apoio técnico oferecido aos professores que atendem ao estudante com deficiência, com conhecimentos gerais e específicos.

\section{Formação discente}

Os cursos de Licenciatura formam profissionais do magistério da Educação Básica, que, conforme a Resolução 02/2015, "compreendem aqueles que exercem atividades de docência e demais atividades pedagógicas, incluindo a gestão educacional dos sistemas de ensino e das unidades escolares de Educação Básica, nas diversas etapas e modalidades de educação" (BRASIL, 2015). Na modalidade Educação Especial, o Decreto 5.626, de 2005, institui que, nos cursos de formação de docentes "a Libras deve ser inserida como disciplina curricular obrigatória" (BRASIL, 2005), e o Estatuto da PCD, a "inclusão em conteúdos curriculares, em cursos de nível superior e de educação profissional técnica e tecnológica, de temas relacionados à pessoa com deficiência nos respectivos campos de conhecimento" (BRASIL, 2015).

A Instituição A oferece a disciplina de Libras, mais a opção de uma disciplina eletiva na área de inclusão, em comum com outras Licenciaturas. Também dispõe de convênios com espaços escolares e não escolares, que oportunizam práticas de educação musical com público-alvo da Educação Especial, como parte integrante dos objetivos pedagógicos e metodológicos de disciplinas da Licenciatura.

A Instituição B tem quatro estágios, sendo um deles multidisciplinar, que pode ser realizado em espaços inclusivos. Na ementa de uma das disciplinas tem o conteúdo Processos Inclusivos na Educação Musical, além de uma disciplina de Arte-inclusão com caráter eletivo.

VALIM, Mariana, PACHECO, Eduardo Guedes. A educação especial e o atendimento educacional especializado no ensino superior de música: um recorte sobre quatro universidades do Estado do Rio Grande do Sul. Revista da FUNDARTE. Montenegro, p.124-144, ano 20, o 40, janeiro/março de 2020.Disponível em: http://.seer.fundarte.rs.gov.br/index.php/RevistadaFundarte/index> 31 de março de 2020 


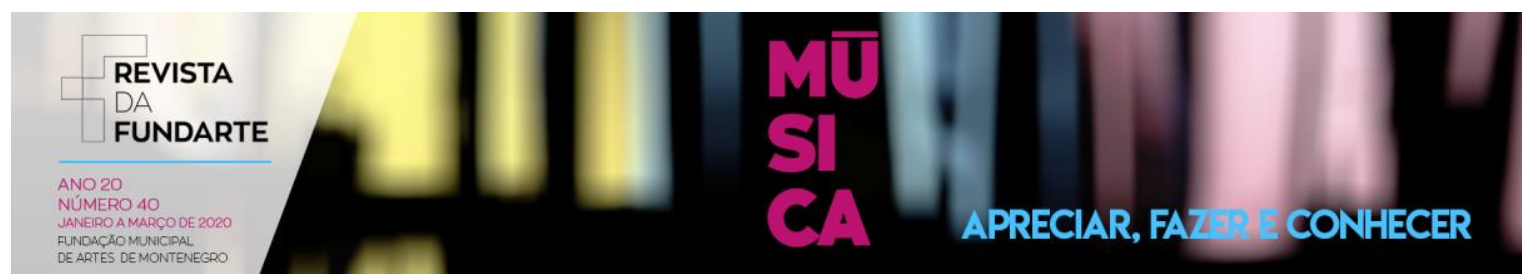

A Instituição C, além da disciplina de Libras, possui em sua matriz curricular a disciplina de Intervenções Músicopedagógicas Inclusivas, no módulo do quarto semestre, que é todo voltado para a inclusão: Educação Especial, Pessoa Idosa e Diversidade. Oferece componentes eletivos e agrupados com um curso de Bacharelado na área da Saúde, que contempla os assuntos de psicopedagogia musical, psicopatologias e desenvolvimento humano. A Instituição D possui duas disciplinas de Educação Especial na Matriz Curricular: Libras e Educação Inclusiva, comum a todas as Licenciaturas.

\section{Formação docente}

O decreto 7.611 de 2011, no artigo 5², prevê apoio técnico para professores, ampliando as ações de Atendimento Educacional Especializado aos estudantes com deficiência, através de formação continuada de professores e formação de gestores, educadores e demais profissionais da escola para a educação, na perspectiva da educação inclusiva.

A Instituição A não faz palestras e seminários específicos na área de Educação Especial, mas realiza formação a cada semestre para os professores que terão demanda de alunos PCD, organizados pelos Núcleos de Apoio. Também possui uma política de incentivo da Instituição, para que os profissionais da educação participem de cursos e formações em suas áreas de interesse.

O coordenador da Instituição $B$ relata que, uma única vez, participou de uma formação nesta Instituição sobre a educação inclusiva em âmbito geral. Afirma que nem todos os professores estejam preparados para a educação inclusiva, principalmente na área de Música, por suas especificidades como escrita e percepção musical. Os motivos são diversos, por exemplo, alguns não tiveram essa abordagem na sua formação, por virem de Licenciaturas mais antigas ou cursos de Bacharelado. Outros não sabem como adaptar os materiais e utilizar os recursos,

VALIM, Mariana, PACHECO, Eduardo Guedes. A educação especial e o atendimento educacional especializado no ensino superior de música: um recorte sobre quatro universidades do Estado do Rio Grande do Sul. Revista da FUNDARTE. Montenegro, p.124-144, ano 20, no 40, janeiro/março de 2020.Disponível em: http://.seer.fundarte.rs.gov.br/index.php/RevistadaFundarte/index> 31 de março de 2020 


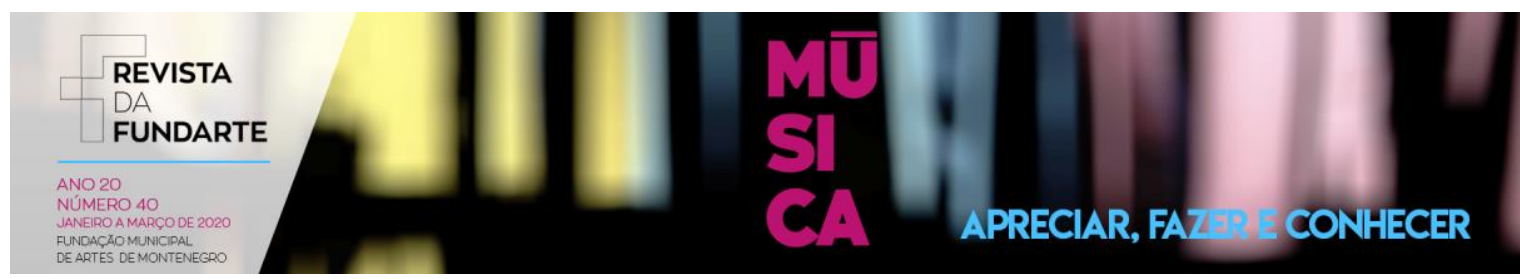

precisando de ajuda especializada; além disso, alguns formam barreiras atitudinais, questionando e invalidando a acessibilidade do estudante PCD.

A Instituição $C$ relata que a equipe de AEE promove apoio ao docente, para Ihe instruir sobre as metodologias e recursos que necessitar, além de cursos de formação de professores, trazendo profissionais que falem sobre as deficiências, conforme as demandas necessárias. A Instituição D oferece cursos e orientações aos professores, promovendo em seu Seminário anual, palestras com profissionais, para formação sobre adaptações e para amenizar as barreiras atitudinais.

\section{Considerações sobre os dados analisados}

Ao conhecer sobre as medidas de acesso ao Ensino Superior de Música da Pessoa com Deficiência nas Instituições pesquisadas, todas atendem à legislação, pois os cursos de licenciatura somente são liberados para o funcionamento, pelos seus respectivos Conselhos, se a Instituição atender às especificações em relação à acessibilidade nos processos seletivos e projetos arquitetônicos. Portanto, a Pessoa com Deficiência que deseja prosseguir sua formação em nível Superior, tem seu direito de ingresso assegurado e assessorado. Porém, de acordo com as falas dos entrevistados, outras barreiras representam desafios para a "participação plena e efetiva na sociedade em igualdade de condições com as demais pessoas" (BRASIL, 2015).

Assim, na maioria das vezes, a Pessoa com Deficiência tem atendido seu processo de ingresso no Ensino Superior de Música, não sendo este o maior de seus entraves, mas nem sempre o mesmo pode-se dizer sobre as condições de permanência e participação. De acordo com os casos analisados, a permanência da Pessoa com Deficiência no Ensino Superior de Música é a grande questão da acessibilidade.

Quanto ao apoio e atendimento ao estudante PCD, pensando em um ensino formativo, com aprendizagens significativas, mostrou-se efetivo 0 trabalho multidisciplinar e integrado, porém com pessoal especializado e exclusivo para as VALIM, Mariana, PACHECO, Eduardo Guedes. A educação especial e o atendimento educacional especializado no ensino superior de música: um recorte sobre quatro universidades do Estado do Rio Grande do Sul. Revista da FUNDARTE. Montenegro, p.124-144, ano 20, no 40, janeiro/março de 2020.Disponível em: http://.seer.fundarte.rs.gov.br/index.php/RevistadaFundarte/index> 31 de março de 2020 


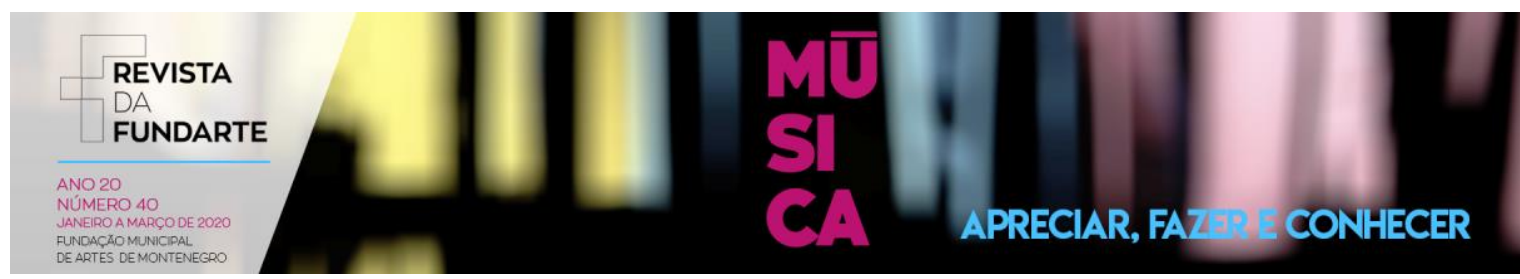

funções de atendimento das necessidades educacionais do estudante PCD. O acúmulo de funções por professores e/ou coordenadores se mostrou não tão eficiente devido à demanda constante de produção de materiais, recursos, assessoria pedagógica aos professores e adequação à legislação. Quanto aos recursos no ensino de Música, os materiais específicos, a linguagem, escrita musical e outras especificidades, trazem a necessidade de profissionais para o atendimento especializado em educação musical inclusiva e conhecedores dos recursos e ajuda técnica, transversais à área de Música e Educação Especial.

As adaptações e avaliações da atividade em música tornam-se um processo contínuo e inclusivo, focado nas potencialidades do estudante PCD, mas que precisa ser fundamentado em elementos que expressem a complexidade da experiência musical. Assim, as adaptações curriculares e avaliações do estudante PCD do curso de Música tornam-se mais eficientes ao serem analisados caso a caso, levando em conta a história do aluno com a Música e suas habilidades, considerando as estratégias de aprendizado musical do aluno durante sua formação anterior e a capacidade de expansão de seu conhecimento musical durante sua formação no Ensino Superior.

Ao falar sobre o ingresso desse aluno no mercado de trabalho do licenciado PCD, não se pode deixar de pensar sobre o papel do professor, do ensino de música e da formação inicial do professor de música. Na sala de aula da Educação Básica, o licenciado de Música encontrará público diverso, incluindo o público-alvo da Educação Especial. Para isso, deverá entender das metodologias de ensino e aprendizagem da Música, para desenvolvimento do conhecimento e habilidade da linguagem musical. A Matriz Curricular dos cursos analisados tem uma pequena oferta de disciplinas ou conteúdo de ementas relacionadas à Educação Especial. Para cursos de 8 semestres em Licenciatura, ofertar duas ou três disciplinas sobre Educação Inclusiva correspondem a uma formação superficial, tendo em vista a demanda que encontrarão como professores em Educação Básica. As práticas de estágios e de vivências pedagógicas diretamente realizadas com o público-alvo da VALIM, Mariana, PACHECO, Eduardo Guedes. A educação especial e o atendimento educacional especializado no ensino superior de música: um recorte sobre quatro universidades do Estado do Rio Grande do Sul. Revista da FUNDARTE. Montenegro, p.124-144, ano 20, no 40, janeiro/março de 2020.Disponível em: http://.seer.fundarte.rs.gov.br/index.php/RevistadaFundarte/index> 31 de março de 2020 


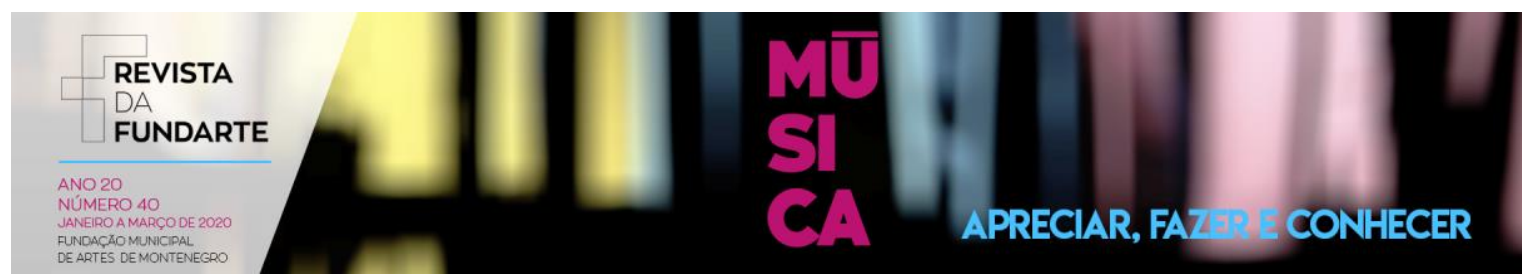

Educação Especial, foram importante recurso na formação do licenciando, ao trazer a Pessoa com Deficiência para práticas dentro da Universidade, ou ao contrário, colocar o licenciando dentro de um espaço de vivência e convivência com alunos PCD, tornando-o espaço de aprendizagem.

A formação de professores que já atuam no Ensino Superior de Música, nos casos analisados, mostrou-se mais no sentido de quebrar barreiras atitudinais, ao explanar para profissionais de carreira sobre as legislações quanto à acessibilidade e atendimentos aos estudantes PCD. O interesse na área e a demanda são os fatores que motivam os professores a buscarem outros cursos e formações mais específicas.

Por todos estes motivos, a presença do estudante com deficiência no Ensino Superior de Música cria demanda e fomenta a produção de materiais, técnicas e conhecimentos, assim como sua presença como docente em educação musical, atuando como educador e multiplicador das aplicações das letras da lei na Inclusão.

Pela especificidade da linguagem musical e a recente possibilidade de acessibilidade da PCD ao Ensino Superior de Música, as ações ainda se mostram em experimentação e formação, porém as Instituições muito têm a crescer ao assumirem seu papel social de multiplicadores de saberes e referência em educação, compartilhando as vivências, democratizando o acesso aos saberes e fomentando as pesquisas na área. A formação de professores não pode mais deixar de atender à visão de propiciar aprendizagens a todos os tipos de alunos, através de mediação de conhecimentos com todos os tipos de públicos, inclusive o público-alvo da Educação Especial. Talvez os primeiros alunos PCD egressos dos cursos de Licenciatura em Música possuam algumas lacunas em sua formação, devido às dificuldades e aos pioneirismos que protagonizarão durante sua caminhada na graduação, mas terão contribuição muito importante ao poderem tornar-se voz ativa e multiplicadores das técnicas e pesquisas, cada um de seu lugar, entendendo que o Ensino Superior, em especial as Licenciaturas, tem uma função social na formação e informação de pessoas, através de uma educação cada vez mais superior.

VALIM, Mariana, PACHECO, Eduardo Guedes. A educação especial e o atendimento educacional especializado no ensino superior de música: um recorte sobre quatro universidades do Estado do Rio Grande do Sul. Revista da FUNDARTE. Montenegro, p.124-144, ano 20, o 40, janeiro/março de 2020.Disponível em: http://.seer.fundarte.rs.gov.br/index.php/RevistadaFundarte/index> 31 de março de 2020 


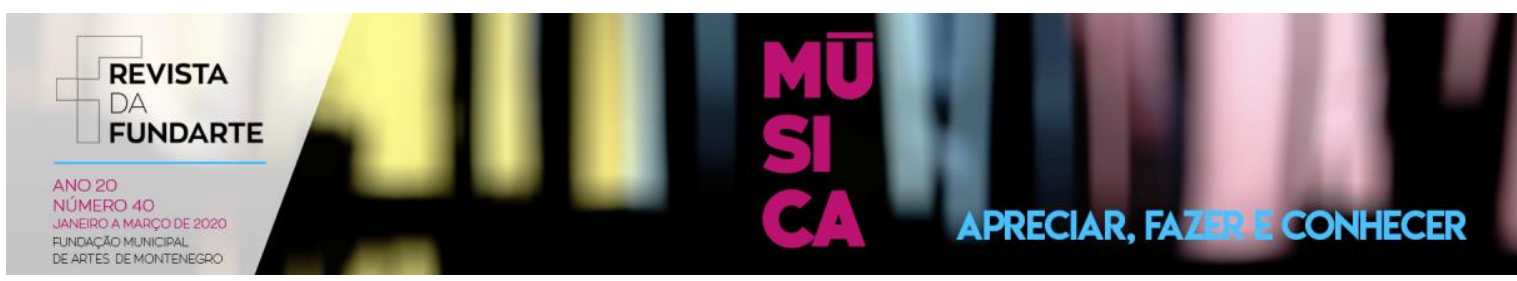

\section{Referências:}

BARROSO, Maria Aida. Música e Inclusão nas Universidades. In: LOURO, Viviane dos Santos (Org.) Música e Inclusão: múltiplos olhares. São Paulo: Editora Som, 2016.

BRASIL. Lei no 9.394, de 20 de dezembro de 1996. Estabelece as diretrizes e bases da educação nacional. Disponível em: <http://www.planalto.gov.br/ccivil_03/leis/L9394.htm> Acesso em: 10 nov. 2017.

BRASIL. Decreto $n^{\circ} 5.626$, de 22 de dezembro de 2005. Regulamenta a Lei $n^{\circ}$ 10.436, de 24 de abril de 2002, que dispõe sobre a Língua Brasileira de Sinais Libras, e 0 art. 18 da Lei no 10.098, de 19 de dezembro de 2000. Diário Oficial [da) República Federativa do Brasil, Brasília, DF, 23 dez. 2005. Disponível em:<http://www.planalto.gov.br/ccivil_03/_Ato2004-2006/2005/Decreto/D5626.htm> Acesso em 25 out. 2018.

BRASIL. Política Nacional de educação especial na perspectiva da educação inclusiva. Brasília, MEC, 2008. Disponível em: <http://portal.mec.gov.br/seesp/arquivos/pdf/politica.pdf>. Acesso em: 10 nov. 2017.

BRASIL. Decreto n. ${ }^{\circ} 6.571$, de 17 de setembro de 2008. Dispõe sobre o atendimento educacional especializado, regulamenta o parágrafo único do art. 60 da Lei $\mathrm{n}$.. 9.394, de 20 de dezembro de 1996, e acrescenta dispositivo ao Decreto n. 6.253 , de 13 de novembro de 2007. Diário Oficial da União, Brasília, DF, 2008c. Disponível em: <http://www.planalto.gov.br/ccivil_03/_ato2007-2010/2008/Decreto/D6571.htm> Acesso em: 10 nov. 2017.

BRASIL. Ministério da Educação. Parecer CNE/CEB $n^{\circ}$ 13/2009, de 24 de setembro de 2009. Diretrizes Operacionais para o atendimento educacional especializado na Educação Básica, modalidade Educação Especial. Disponível em: $<$ http://portal.mec.gov.br/dmdocuments/pceb013_09_homolog.pdf>. Acesso em: 10 nov. 2017.

BRASIL. Decreto n.o 7.611, de 17 de novembro de 2011. Dispõe sobre a Educação Especial, o atendimento educacional especializado e dá outras providências. Diário Oficial da União, Brasília, DF, 18 nov. 2011b. Disponível em: <http://www.planalto.gov.br/ccivil_03/_Ato2011-2014/2011/Decreto/D7611.htm>.

Acesso em: 10 nov. 2017.

BRASIL. Secretaria de Educação Básica. Diretrizes Curriculares Nacionais da Educação Básica. Brasília: MEC, SEB, DICEI, 2013.

VALIM, Mariana, PACHECO, Eduardo Guedes. A educação especial e o atendimento educacional especializado no ensino superior de música: um recorte sobre quatro universidades do Estado do Rio Grande do Sul. Revista da FUNDARTE. Montenegro, p.124-144, ano 20, no 40, janeiro/março de 2020.Disponível em: http://.seer.fundarte.rs.gov.br/index.php/RevistadaFundarte/index> 31 de março de 2020 


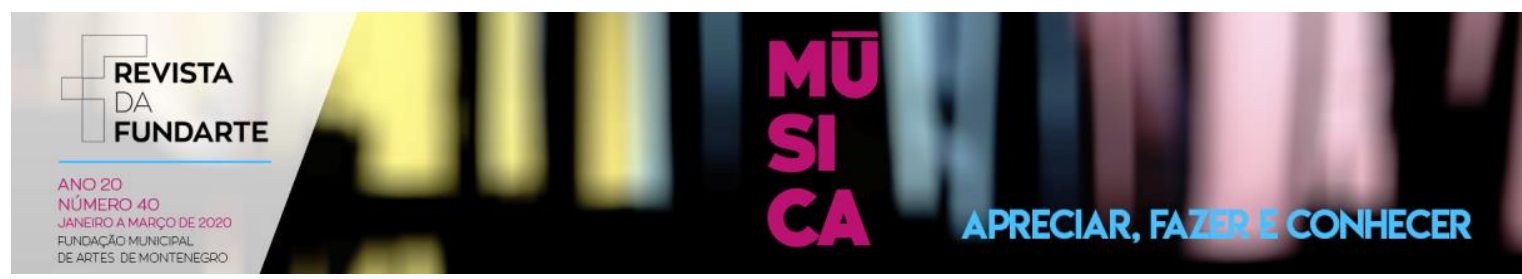

BRASIL. Ministério da Educação. Nota Técnica 04/2014, de 23 de janeiro de 2014. Orientação quanto a documentos comprobatórios de alunos com deficiência, transtornos globais do desenvolvimento e altas habilidades/superdotação no Censo Escolar. Disponível em: <http://portal.mec.gov.br/index.php?option=com_docman\&view=download\&alias=15 898-nott04-secadi-dpee-23012014\&category_slug=julho-2014-pdf\&ltemid=30192 > Acesso em: 22 set. 2018.

BRASIL. Resolução № 2, de 1ํ de julho de 2015. Define as Diretrizes Curriculares Nacionais para a formação inicial em nível superior (cursos de licenciatura, cursos de formação pedagógica para graduados e cursos de segunda licenciatura) e para a formação continuada. Brasília, MEC, 2015. Disponível em <http://portal.mec.gov.br/docman/agosto-2017-pdf/70431-res-cne-cp-002-03072015pdf/file>. Acesso em 22 set. 2018.

BRASIL. Lei no 13.146, de 6 de julho de 2015. Institui a Lei Brasileira de Inclusão da Pessoa com Deficiência (Estatuto da Pessoa com Deficiência). Diário Oficial da União, Brasília, 7 de julho de 2015. Disponível em: <http://www.planalto.gov.br/ccivil_03/_ato2015-2018/2015/Lei/L13146.htm>. Acesso em: 23 mar. 2017.

LOPES, Maura Corcini; HATTGE, Morgana Domênica (org.). Inclusão escolar: conjunto de práticas que governam. Belo Horizonte: Autêntica Editora, 2009.

LOURO, Viviane dos Santos; ALONSO, Luís Garcia; ANDRADE, Alex Ferreira de (org.). Educação musical e deficiência: propostas pedagógicas. São José dos Campos: Ed. do Autor, 2006.

LOURO, Viviane dos Santos. Fundamentos da aprendizagem musical da pessoa com deficiência. $1^{\circ}$ edição. São Paulo: Editora Som, 2012.

LOURO, Viviane dos Santos (org.) Música e Inclusão: múltiplos olhares. São Paulo: Editora Som, 2016.

SILVA, Helena Lopes da; ZILLE, José Antônio Baêta (Org.). Música e Educação. Barbacena: EdUEMG, 2015. (Série Diálogos com o Som. Ensaios; v.2)

VALIM, Mariana, PACHECO, Eduardo Guedes. A educação especial e o atendimento educacional especializado no ensino superior de música: um recorte sobre quatro universidades do Estado do Rio Grande do Sul. Revista da FUNDARTE. Montenegro, p.124-144, ano 20, no 40, janeiro/março de 2020.Disponível em: http://.seer.fundarte.rs.gov.br/index.php/RevistadaFundarte/index> 31 de março de 2020 